\title{
Influence of the Thermal Parameters and the Structural Parameters on the Performance of Clutch Pressure Plate
}

\author{
JIN Chao ${ }^{1, \text { a }}$, GONG Yu-bing ${ }^{1, b}$, PAN Shun-ying ${ }^{2, \mathrm{c}}$ and ZHANG De-feng ${ }^{1, \mathrm{~d}}$ \\ ${ }^{1}$ School of Mechanical \& Electrical Engineering, Guilin University of electronic technology, Guilin, \\ Guangxi, 541004, China \\ ${ }^{2}$ GUILIN FUDA CO., LTD, Guilin, Guangxi, 541199, China \\ a952016008@qq.com, ${ }^{\mathrm{b}}$ gybcome@163.com, ${ }^{\mathrm{c}} 455652586 @ q q . c o m,{ }^{\mathrm{d}} 784112123 @ q q . c o m$
}

Keywords: clutch pressure plate; thermal deformation; FEM; structural parameters.

Abstract. The clutch pressure plate was easy to produce high temperature and axial thermal deformation under the extreme operation conditions, which results in clutch ablation, torque transmission capacity /slip faults. In this paper, a new channel clutch pressure plate was proposed that set a radial cooling channels and axial cooling through holes on the traditional pressure plates. Based on the finite element modeling and analysis of the new pressure plate, the influence of the thermal parameters (such as ambient temperature, convective heat transfer coefficient of the friction surface and the non-friction surfaces) and structural parameters (such as the width and height of the radial cooling channels, the diameter of the axial cooling through holes, etc.) on the temperature field and deformation field of new pressure plate were obtained. The results show that the effect of the thermal parameters on the performance of the new pressure plate was not obvious, but the influence of the structural parameters on the thermal deformation of the new pressure plate was significant. Compared to the performance of the original pressure plate, the performance of the new scheme has been improved significantly.

\section{Introduction}

Clutch is an important part of automotive transmission, and the pressure plate is one of the main parts of the clutch. During the automobile starting, the clutch pressure plate and the friction plate realize torque transmission through relative sliding. In the process of clutch engagement, the heat generated by friction will rapidly raise the temperature of the pressure plate, thereby accelerating the abrasion of pressure plate. On the other hand, the thermal deformation caused by temperature rise will reduce the friction area between the pressure plate and the frictional plate which eventually results in incomplete clutch release ${ }^{[1]}$. Especially for the large-scale construction vehicles such as heavy-duty trucks, due to bad road conditions, the distribution of temperature field and deformation field is more complex and the peak value of the temperature and deformation of the press plate is higher; the clutch pressure plate is prone to cases such as erosion, cracking, etc., resulting in early failure ${ }^{[2]}$.

For the above cases, in this paper, a new channel clutch pressure plate is proposed, and namely, the radial cooling channel and axial thermal through-hole are set in the traditional structure of the pressure plate. The design has won the authorization of national patent for utility models (A channel clutch pressure plate, ZL201510049547.5). To explore the performance of channel pressure plate and its influencing factors, this paper starts with the thermal parameters (including ambient temperature, convective heat transfer coefficient of pressure plate friction surface and non- abrasive surface, etc.) and structural parameters (including radial cooling channel width and height, and axial thermal through-hole diameter, etc.), making thermal-structure coupling analysis of the pressure plate, gaining influence law of the thermal parameters and structural parameters on the temperature field and deformation field. The results show that the thermal parameters have little effect on the working performance of the new pressure plate, and structural parameters have a greater impact on the thermal deformation amount of the new pressure plate. Compared to the original pressure plate program, the new pressure plate has significantly improved working performance. 


\section{ANSYS sensitivity analysis based on Spearman's rank correlation coefficient}

Assuming that the sensitivity of structural response y (for example, the maximum displacement) to the structural parameters $\mathrm{x}_{1}, \mathrm{x}_{2}, \ldots, \mathrm{x}_{\mathrm{m}}$ (for example, $\mathrm{m}$ is cross-sectional area of rod piece) is examined, firstly, the probability distribution function of each specified structural parameter is $\mathrm{x}_{1}$, $\mathrm{x}_{2}, \ldots, \mathrm{x}_{\mathrm{m}}$, and subsequently, in stochastic simulation, the value distribution of each structural parameter is based on its probability distribution function. Supposed that $n$ times of stochastic simulation calculation are conducted to obtain $n$ structural response values of $\mathrm{y}_{1}, \mathrm{y}_{2}, \ldots, \mathrm{y}_{\mathrm{n}}$. Among them, the structural response of $\mathrm{i}$-th simulation operation is $\mathrm{y}_{\mathrm{i}}$, and structural parameters are $\mathrm{x}_{1 \mathrm{i}}, \mathrm{x}_{2 \mathrm{i}}, \ldots$, $\mathrm{x}_{\mathrm{mi}}, \mathrm{i}=1,2, \ldots, \mathrm{n}$.

The following $m$ data pairs are constituted of sample values of $x_{j 1}, x_{j 2}, \ldots, x_{j n}$ for the $j$-th $(j=1,2, \ldots$, $\mathrm{m})$ structural parameter in the n-th stochastic simulation calculations and response sample values of $\mathrm{y}_{1}, \mathrm{y}_{2}, \ldots, \mathrm{y}_{\mathrm{n}}$ for operational structure in the $\mathrm{n}$-th stochastic simulation:

$$
\left\{\begin{array}{c}
x_{j 1} \\
y_{1}
\end{array}\right\},\left\{\begin{array}{c}
x_{j 2} \\
y_{2}
\end{array}\right\}, \ldots\left\{\begin{array}{c}
x_{j n} \\
y_{n}
\end{array}\right\}, j=1,2, \ldots, m
$$

For each data pair, its Spearman's rank correlation coefficient $r_{s j}(j=1,2, \ldots, m)$ is figured out.

$R_{s j}$ reflects the correlation between the structural response $y$ and $j$-th structural parameter, and $r_{s j}$ is positive, indicating that the structural response $\mathrm{y}$ increases with the structural parameter $\mathrm{x}_{\mathrm{j}}$ and decreases with it; on the contrary, it is the opposite. The $\left|r_{s j}\right|$ reflects the degree of correlation between structural response $\mathrm{y}$ and structural parameter $\mathrm{x}_{\mathrm{j}}$, and namely, sensitivity is signified herein. Higher $\left|r_{s j}\right|$ indicates more sensitive structural response y to the structural parameter $x_{j}$, and namely, the impact of changes in structural parameter $\mathrm{x}_{\mathrm{j}}$ is more significant to structural response $\mathrm{y}$; otherwise, it is on the contrary ${ }^{[3]}$.

\section{Modeling and analysis}

\section{Definition of harsh working conditions}

The general joint conditions of the clutch pressure plate have been analyzed in numerous domestic and foreign literatures ${ }^{[4,7]}$, but there is few analysis on complex and harsh working conditions. Failures such as fracture of clutch pressure plate often occur in bad working conditions. In order to fully simulate the harsh working conditions, twice slipping friction work is set in this paper for continuous engagement and disengagement of the clutch for 30 times. Simulation analysis in this paper is carried out in the harsh conditions.

\section{Establishment of finite element model}

Geometrical model of pressure plate is constructed using SolidWorks software, and it is imported into ANSYS software for meshing, and the element size is set to $4 \mathrm{~mm}$. After meshing, the total number of the elements is 139,008 , and the total number of nodes is 441,314 . Finite element model of the pressure plate is shown in the figure 1.

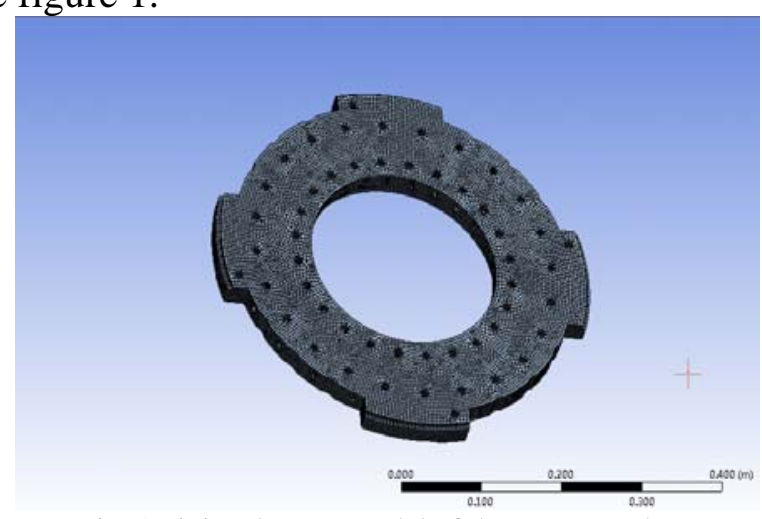

Fig. 1 Finite element model of the pressure plate

Impact of the thermal parameters on the clutch pressure plate performance

To explore the influence of the thermal parameters on the performance of the clutch pressure plate, 
this paper conducts parameter setting from the ambient temperature, convective heat transfer coefficient on friction surface and convective heat transfer coefficient on non-friction surface, as the table 1 below.

Tab. 1 Thermal parameters of pressure plate and their range

\begin{tabular}{|c|c|c|c|}
\hline thermal parameters & $\begin{array}{l}\text { mean } \\
\text { value }\end{array}$ & $\begin{array}{l}\text { minimum } \\
\text { value }\end{array}$ & $\begin{array}{l}\text { maximum } \\
\text { value }\end{array}$ \\
\hline ambient temperature $/{ }^{\circ} \mathrm{C}$ & 110 & 90 & 130 \\
\hline 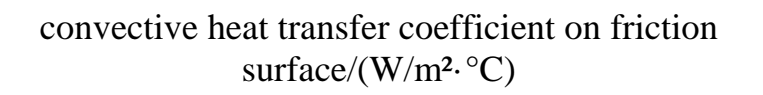 & 160 & 70 & 230 \\
\hline 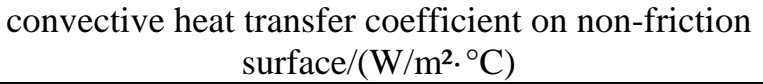 & 140 & 70 & 230 \\
\hline
\end{tabular}

Heat flux density on the surface of the pressure plate is calculated and applied as the boundary condition of the finite element model. Thermal-structure coupling analysis of the pressure plate is made using ANSYS to obtain the highest temperature and the maximum axial thermal deformation of the pressure plate under different thermal parameters, as shown in Figure 2.

\begin{tabular}{|c|c|c|c|c|c|c|}
\hline No. & $\begin{array}{l}\text { Ambient temperature of } \\
\text { non-friction surface } /{ }^{\circ} \mathrm{C}\end{array}$ & $\begin{array}{l}\text { Convective heat transfer coefficient } \\
\text { of non- friction surface }\left(\left(\mathrm{W} / \mathrm{m}^{2}{ }^{\circ}{ }^{\circ} \mathrm{C}\right)\right.\end{array}$ & $\begin{array}{l}\text { Ambient temperature of } \\
\text { friction surface }{ }^{\circ} \mathrm{C}\end{array}$ & $\begin{array}{l}\text { Convective heat transfer coefficient } \\
\text { of friction surface }\left(\left(\mathrm{W} / \mathrm{m}^{2} \cdot{ }^{\circ} \mathrm{C}\right)\right.\end{array}$ & $\begin{array}{l}\text { Maximum temperature } \\
\text { of pressure plate } /{ }^{\circ} \mathrm{C}\end{array}$ & $\begin{array}{l}\text { Axial deformation of } \\
\text { pressure plate } \mathrm{mm}\end{array}$ \\
\hline 1 & 110 & 150 & 110 & 150 & 356.18 & 0.18638 \\
\hline 2 & 95.916 & 93.664 & 95.916 & 93.664 & 367.38 & 0.1931 \\
\hline 3 & 124.08 & 93.664 & 95.916 & 93.664 & 374.36 & 0.19255 \\
\hline 4 & 95.916 & 206.34 & 95.916 & 93.664 & 337.04 & 0.17658 \\
\hline 5 & 124.08 & 206.34 & 95.916 & 93.664 & 349.74 & 0.18048 \\
\hline 6 & 95.916 & 93.664 & 124.08 & 93.664 & 367.47 & 0.19315 \\
\hline 7 & 124.08 & 93.664 & 124.08 & 93.664 & 374.45 & 0.19259 \\
\hline 8 & 95.916 & 206.34 & 124.08 & 93.664 & 337.11 & 0.17664 \\
\hline 9 & 124.08 & 206.34 & 124.08 & 93.664 & 349.81 & 0.18053 \\
\hline 10 & 95.916 & 93.664 & 95.916 & 206.34 & 367.18 & 0.193 \\
\hline 11 & 124.08 & 93.664 & 95.916 & 206.34 & 374.16 & 0.19245 \\
\hline 12 & 90 & 150 & 110 & 150 & 348.9 & 0.18405 \\
\hline 13 & 95.916 & 206.34 & 95.916 & 206.34 & 336.89 & 0.17647 \\
\hline 14 & 124.08 & 206.34 & 95.916 & 206.34 & 349.59 & 0.18037 \\
\hline 15 & 95.916 & 93.664 & 124.08 & 206.34 & 367.38 & 0.1931 \\
\hline 16 & 124.08 & 93.664 & 124.08 & 206.34 & 374.36 & 0.19255 \\
\hline 17 & 95.916 & 206.34 & 124.08 & 206.34 & 337.04 & 0.17659 \\
\hline 18 & 124.08 & 206.34 & 124.08 & 206.34 & 349.74 & 0.18048 \\
\hline 19 & 130 & 150 & 110 & 150 & 363.45 & 0.18643 \\
\hline 20 & 110 & 70 & 110 & 150 & 377.56 & 0.19555 \\
\hline 21 & 110 & 230 & 110 & 150 & 338.6 & 0.17516 \\
\hline 22 & 110 & 150 & 90 & 150 & 356.09 & 0.18632 \\
\hline 23 & 110 & 150 & 130 & 150 & 356.27 & 0.18644 \\
\hline 24 & 110 & 150 & 110 & 70 & 356.27 & 0.18643 \\
\hline 25 & 110 & 150 & 110 & 230 & 356.09 & 0.18632 \\
\hline
\end{tabular}

Fig. 2 The highest temperature and the axial thermal deformation of the pressure plate under different thermal parameters

It can be obtained from the numerical analysis of the Figure 2 that under different thermal parameters, the maximum temperature of the pressure plate is $377.56{ }^{\circ} \mathrm{C}$, and the lowest temperature is $336.89{ }^{\circ} \mathrm{C}$. The range of the thermal parameters affecting the highest temperature of pressure plate is about $40{ }^{\circ} \mathrm{C}$, accounting for 10.8 percent. The maximum axial deformation of the pressure plate is $0.19555 \mathrm{~mm}$, and its minimum axial deformation is $0.17516 \mathrm{~mm}$; the range of the thermal parameters affecting axial thermal deformation is around $0.02 \mathrm{~mm}$, accounting for $10.4 \%$ of the maximum axial deformation.

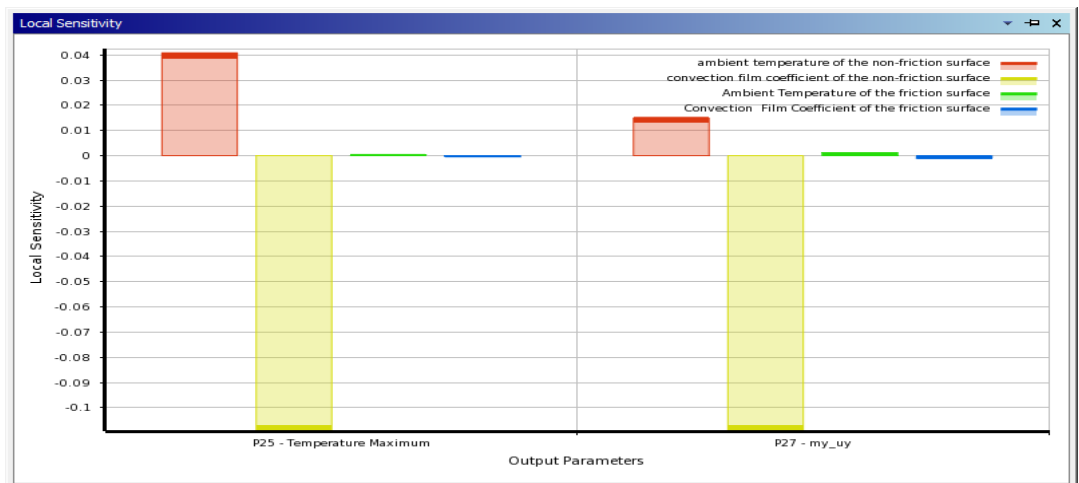

Fig. 3 Sensitivity of the thermal parameters to the highest temperature and the axial deformation of the clutch pressure plate

The figure 3 shows the sensitivity of the thermal parameters to the highest temperature and the axial deformation of the clutch pressure plate. Analysis from the figure 3 shows that the impact of ambient temperature on non-friction surface and convective heat transfer coefficient is greater, and especially the impact of convective heat transfer coefficient on non-friction surface is most obvious. The ambient temperature on non-friction surface is positively correlated to the highest temperature 
and the axial deformation of the clutch pressure plate, and convective heat transfer coefficient on non-friction surface is negatively correlated to convective heat transfer coefficient of pressure plate. Namely, the higher the temperature of ambient temperature on non-friction surface is, the greater the highest temperature and the axial deformation of the pressure plate will be; the greater convective heat transfer coefficient on non-friction surface is, the smaller the highest temperature and the axial deformation of the pressure plate will be. There is basically no influence on ambient temperature and convective heat transfer coefficient on the friction surface. This is because the friction surface is the main heat source during the clutch engagement process, and it has short time in atmospheric convective heat transfer and small contact area. Non- friction surface always performs convective heat transfer during engagement and disengagement process, which is in line with the basic theory of heat transfer theory ${ }^{[8]}$.

Impact of structural parameters on the clutch pressure plate performance

To explore the influence of the structural parameters on the performance of the clutch pressure plate, this paper conducts parameter setting from the distance between radial cooling channel and friction surface, the width and height of the radial cooling channel, the diameter of axial cooling through-hole, as shown in Table 2.

Tab. 2 Structural parameters of pressure plate and their range

\begin{tabular}{cccc}
\hline geometry parameters & mean & minimum & maximum \\
& value & value & value \\
\hline distance between radial cooling channel and friction surface $/ \mathrm{mm}$ & 5 & 4 & 9 \\
width of radial cooling channel/mm & 4 & 4 & 20 \\
height of radial cooling channel/mm & 10 & 5 & 20 \\
diameter of axial through-hole (close to inner ring)/mm & 10 & 5 & 20 \\
diameter of axial through-hole(close to outer ring)/mm & 10 & 5 & 20 \\
\hline
\end{tabular}

The 30 consecutive engagement and disengagement process is performed, and thermal-structure coupling analysis of clutch is made using ANSYS to obtain the maximum temperature and maximum axial thermal deformation of the different structural parameters, as shown in Figure 4.

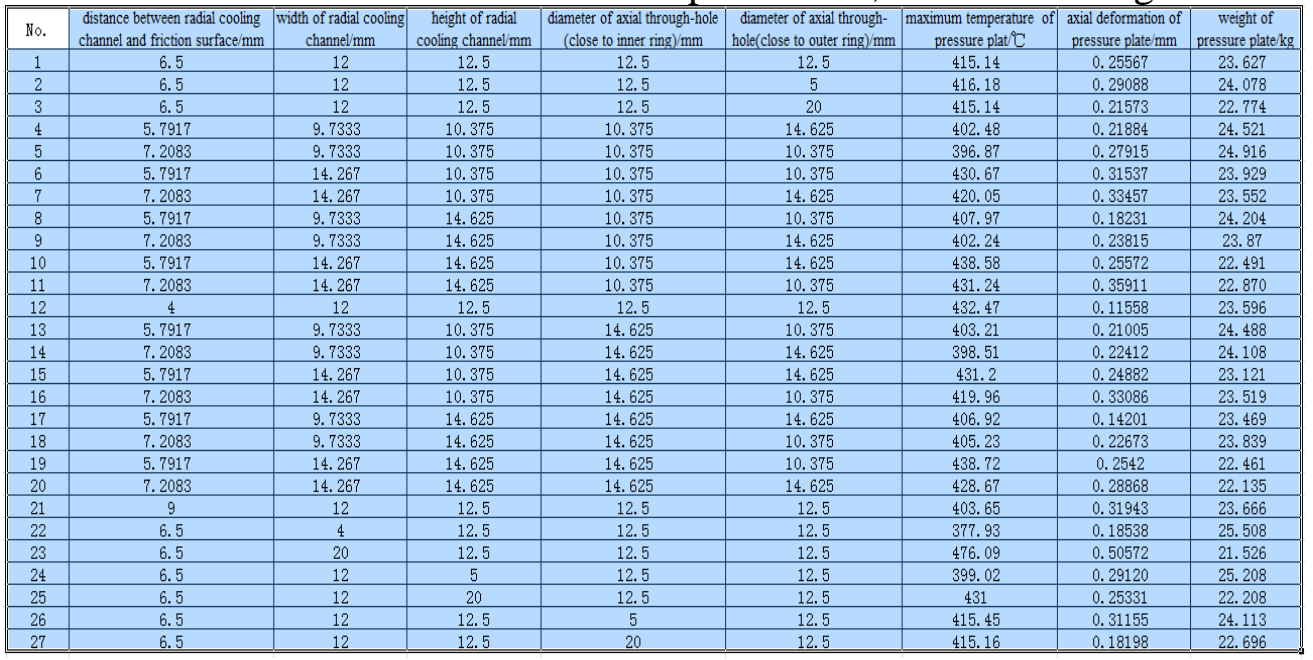

Fig. 4 The highest temperature and maximum axial thermal deformation of pressure plate under different structural parameters

It can be obtained from the Figure 4 that under different structural parameters, the maximum temperature of the pressure plate is $476.09^{\circ} \mathrm{C}$, and the lowest temperature is $377.93^{\circ} \mathrm{C}$. The range of the thermal parameters affecting the highest temperature of pressure plate is about $98^{\circ} \mathrm{C}$, accounting for $20.6 \%$; the maximum axial deformation of pressure plate is $0.50572 \mathrm{~mm}$, and its minimum axial deformation is $0.11558 \mathrm{~mm}$; the range of the thermal parameters affecting axial thermal deformation is about $0.39 \mathrm{~mm}$, accounting for $77.1 \%$ of the maximum axial deformation. The maximum mass of pressure plate is $25.508 \mathrm{~kg}$, while the minimum mass is $21.526 \mathrm{~kg}$; the range of structural parameters affecting the mass of pressure plate is about $4 \mathrm{~kg}$, accounting for $15.6 \%$ of the largest value. 


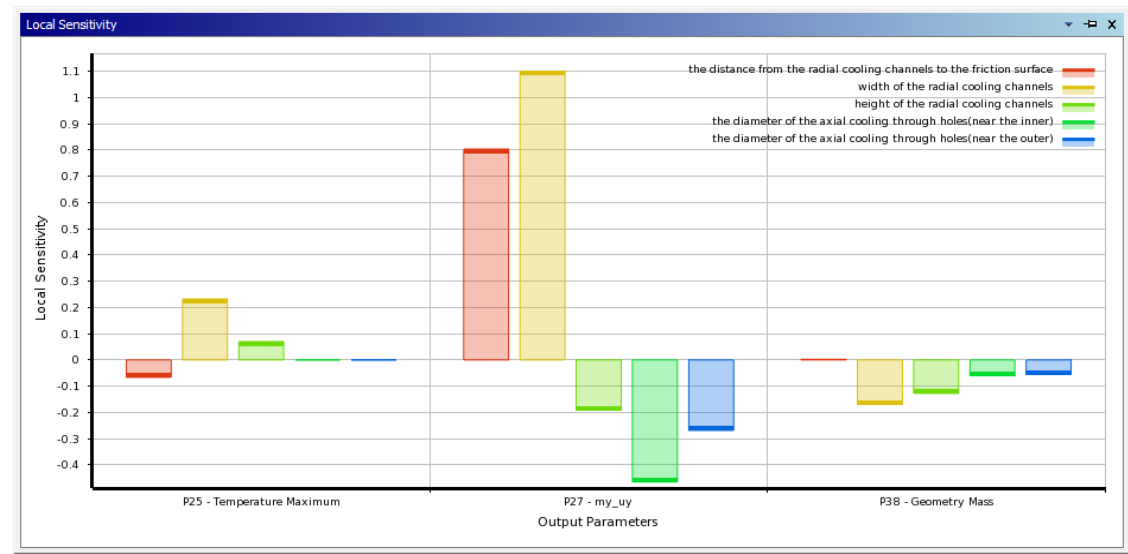

Fig. 5 Sensitivity of structural parameters to the highest temperature and the axial deformation of the clutch pressure plate

The figure 5 shows the sensitivity of the structural parameters to the highest temperature and the maximum axial deformation of the clutch pressure plate. The highest temperature: it is negatively correlated to the distance between the radial cooling channel to the friction surface, while positively correlated to the width and height of radial cooling channel. The distance between the radial cooling channel to friction surface, and width and height of radial cooling channel are highly influenced. In particular, the impact of the width of the radial cooling channel is the greatest. There is basically no influence of the axial through -hole. The distance between the radial cooling channel to the friction surface and the width of radial cooling channel are positively correlated and greatly affected. The height of radial cooling channel and axial through-hole diameter are negatively correlated. Pressure plate weight: there is basically no influence on the distance between the radial cooling channel to the friction surface. The width and height of the radial cooling channel and axial through-hole diameter are negatively correlated and slightly affected.

To reduce the maximum temperature and the axial deformation of the pressure plate and to reduce the mass of the pressure plate, the optimized structural parameters and results of the pressure plate are obtained and validated. As shown in the figure 6, it is proven that the results of the optimized pressure plate based on the response surface optimization and the actually verified results based on the FEM simulation: the maximum temperature error is $1.2 \%$, the error of pressure plate weight is $1.1 \%$, and the error of axial deformation is $5.5 \%$, which complies with the basic requirements of optimum structural design.

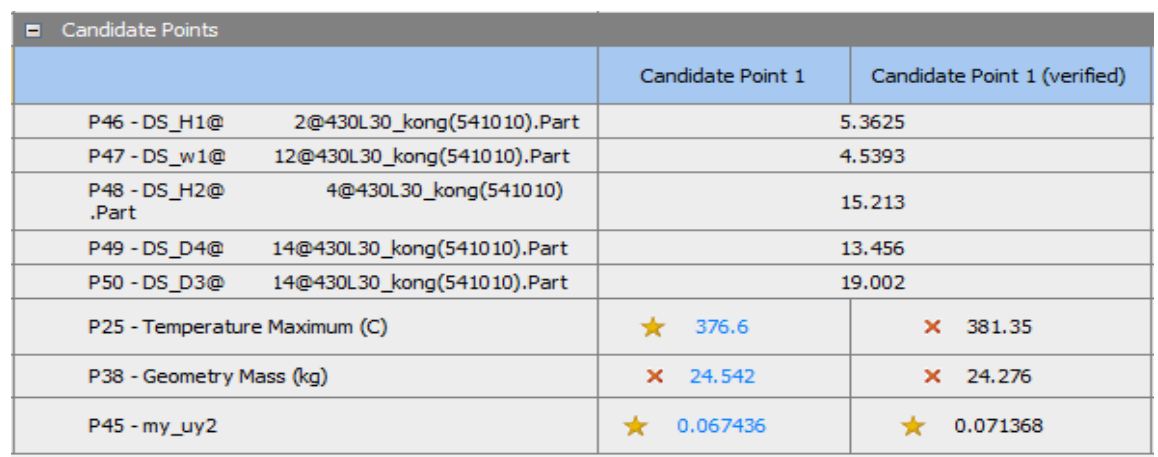

Fig. 6 Optimized structural parameters and results verification

To facilitate manufacturing process available, the approximate values of the optimized structural parameters are taken, which is namely that the distance between radial cooling channel to friction surface is $5.4 \mathrm{~mm}$; the width of the radial cooling channel is $4.5 \mathrm{~mm}$; the height of the radial cooling channel is $15.2 \mathrm{~mm}$; the axial through-hole diameter (near inner side) is $13.5 \mathrm{~mm}$, and axial through -hole diameter (closer to the outer side) is $19.0 \mathrm{~mm}$. Compared with the original pressure plate, the maximum temperature of the optimized pressure plate remains constant. The new optimized pressure plate has reduced weight of $3.5 \mathrm{~kg}$, which is conducive to lightweight clutch and reduces production costs. The axial deformation amount of the new pressure plate is decreased from original $0.29 \mathrm{~mm}$ to $0.07 \mathrm{~mm}$, and the axial deformation is significantly reduced. The working life and the reliability of the optimized pressure plate have been improved significantly. 


\section{Conclusions}

(1) Within the considered parameters scope, the impact of the thermal parameters on the maximum temperature and the axial deformation of the clutch pressure plate is not obvious, and the fluctuation range is about $10 \%$, of which the impact on convective heat transfer coefficient of non-friction surface is the greatest, and there is basically no influence on ambient temperature of friction surface and convective heat transfer coefficient.

(2) Within the size range considered, the impact of the structural parameters on the highest temperature and axial deformation of the clutch pressure plate is greater, of which range of the highest temperature variation has reached 20.6\%; range of axial deformation variation has reached $77.1 \%$. The maximum impact factor for maximum temperature of pressure plate is width of radial cooling channels and they are positively correlated. The maximum impact factor for the axial deformation of the pressure plate is the distance between the radial cooling channel and the friction surface as well as width of radial cooling channel and they are positively correlated respectively.

(3) The maximum temperature of the clutch pressure plate after size optimization is $380.79^{\circ} \mathrm{C}$, and the axial deformation is reduced from $0.29 \mathrm{~mm}$ to $0.07 \mathrm{~mm}$, and there is weight loss of $3.5 \mathrm{Kg}$. Working performance of the optimized pressure plate has been improved significantly.

\section{Acknowledgements}

This work was financially supported by the Guangxi key laboratory of Manufacturing system \& Advanced Manufacturing technology( Granted No. 14-045-15-001Z) and the Scientific Research Project of Guangxi Education Department(Granted No. LD14065B).

\section{References}

[1] ZHU Maotao, LIU Xuelai, GU Yaxin. Thermal-structural coupling analysis on clutch pressure plate during automobile starting: 2013 SAE-China Congress [Z] Beijing China: 20134. (In Chinese)

[2] ZHANG Fan, BAO Jiping. Thermal stress analysis and improvement with FEM of clutch pressure plate in heavy trucks [J]. Forestry Machinery and Woodworking Equipment, 2011, 39(4 ): 23-26. (In Chinese)

[3] YANG Dabin, ZHANG Yigang, Wu Jinzhi. Sensitivity analysis based on ANSYS and its application in single-layer latticed shell [J]. World Earthquake Engineering, 2009 (04 ): 87-91. (In Chinese)

[4] ZHANG Liang, SHI Dong Yan, ZHANG Cheng, et al. Thermal-stress coupled analysis during process of clutch engagement [J] Science Technology and Engineering,2011 ( 26 ): 6303-6307. (In Chinese)

[5] Abdullah O I, Schlattmann J. Finite element analysis of temperature field in automotive dry friction clutch[J]. Tribology in Industry, 2012(No.4): 206-216.

[6] Akhtar, Jamil M M, Schlattmann, et al. Transient thermoelastic analysis of dry clutch system[J]. Machine Design. 2013, 5(4): 141-150.

[7] Abdullah O I, Schlattmann J. An investigation into the thermal behavior of the grooved dry friction clutch[J]. Journal of Tribology. 2014, 136(3): 34504.

[8] CHEN Weihan, XU Guoliang, JIN Shiping. Heat transfer theory [M]. Wuhan: Wuhan University Press, 2004. (In Chinese) 